\title{
Chapter 2 \\ Teaching Units as the Integrating Core of Mathematics Education
}

\begin{abstract}
How to integrate mathematics, psychology, pedagogy and practical teaching within the didactics of mathematics in order to get unified specific theories and conceptions of mathematics teaching? This problem-relevant for theoretical and empirical studies in mathematics education as well as for teacher training-is considered in the present paper. The author suggests an approach which is based on teaching units (Unterrichtsbeispiele). Suitable teaching units incorporate mathematical, pedagogical, psychological and practical aspects in a natural way and therefore they are a unique tool for integration. It is the aim of the present paper to describe an approach to bridging the often deplored gap between didactics of mathematics teaching on one hand and teaching practice, mathematics, psychology, and pedagogy on the other hand. In doing so I relate the various aspects of mathematics education to one another. My interest is equally directed to teacher training and to the methodology of research in mathematics education. The structure of the paper is as follows. First I would like to make reference to and characterize an earlier discussion on the status and role of mathematics education; secondly, I will talk about problems of integration which naturally arise when mathematics education is viewed as an interdisciplinary field of study. The fourth and essential section will show how to tackle these problems by means of teaching units. The present approach is based on a certain conception of mathematics teaching which is necessary for appreciating Sect. 4. This conception is therefore explained in Sect. 3.
\end{abstract}

\section{Discussion of the Status and Role of Mathematics Education}

In spite of the important progress in international cooperation on mathematics education achieved during the last decade, discussions on the specific quality of mathematics education (or didactics of mathematics) were mainly restricted to the national level. As for the situation in Germany it was only at the 5th Annual Meeting on

This paper is a modified version of the opening address given by the author at the 14th Annual Meeting of German Mathematics Educators, Darmstadt, March 1981.

E. C. Wittmann, Connecting Mathematics and Mathematics Education, https://doi.org/10.1007/978-3-030-61570-3_2 
Mathematics Education (1971) in Bayreuth that H. G. Steiner stimulated a broad discussion on this issue leading to a series of papers on the status and role of mathematics education (Bigalke et al. 1974).

The picture of mathematics education emerging in this way was not at all homogeneous - and it is still not so today. However, restricting attention to the views of those authors who work as professional mathematics educators in research as well as in teacher training reveals a remarkable agreement: mathematics education (didactics of mathematics) is considered as a discipline of its own related intrinsically to mathematics, psychology, pedagogy, and some other fields of study, as well as to the practice of mathematics teaching (cf. Fig. 1).

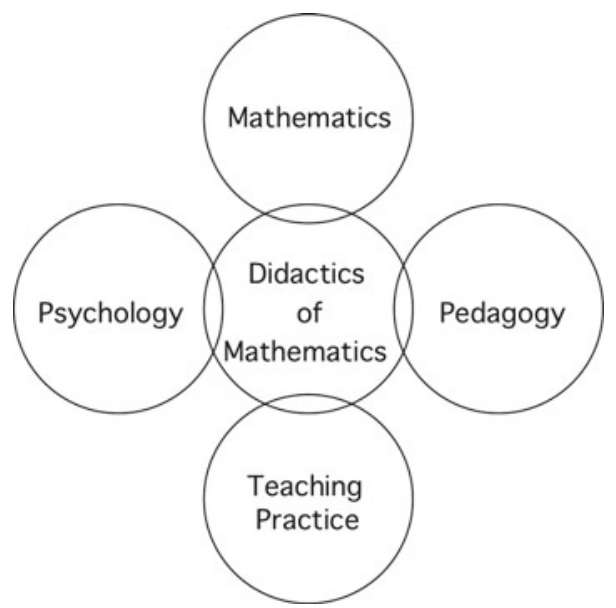

Fig. 1 Didactics of mathematics and the surrounding disciplines

Corresponding to Fig. 1 the memorandum of the "Gesellschaft für Didaktik der Mathematik" on teacher training (March 1981) has described mathematics education as follows:

It is the task of the teacher to combine mathematical knowledge, psychological experience, and a positive attitude towards young people in order to stimulate and support the learning of students towards educational goals beyond mathematics. The teacher's thinking and doing is characterized by taking into account the interlacing of mathematical, pedagogical, psychological and practical conditions and by making balanced decisions. Accordingly, a reasonable training of mathematics teachers has to include didactical studies in addition to solid mathematical and educational studies.

It is the didactics of mathematics which in an interdisciplinary manner investigates the complexity of mathematical learning and teaching. As the professional field of study of mathematics teachers it has to introduce the student teachers to the integrative view and practice which are necessary for their profession and to explain the meaning of their educational work in mathematics. The didactics of mathematics relates mathematical and educational studies to one another, and it provides the necessary bridge to teaching practice.

In short, the feature of mathematics education (didactics of mathematics) expressed in this quotation can be described by the catchwords "interdisciplinary", 
"integrative" and "applied". Obviously these requirements are the immediate consequences of the complex working conditions of mathematics teachers.

\section{Problems of Integration}

As we all know it is much easier to postulate interdisciplinarity, integration and applicability than to put them into practice. Apart from inherent issues, we also have to take into account external pressures which push mathematics education in certain directions contrary to interdisciplinarity and integration. Very clear indicators for pressures of this kind are the quite different expectations about mathematics education expressed by specialists of related fields. For example, mathematicians, if they admit the necessity of mathematics education at all, very often consider it to be elementary mathematics. They expect the didactician to be qualified by standards of mathematical research and to keep mathematically alive, at least by working in "a small mathematical garden" (H. Meschkowski). Sometimes practical experience is called for, by which is usually meant naive experience. Possible sympathies of mathematics educators for psychology or pedagogy, however, are criticized or even rejected on the grounds that they lead away from mathematics. On the other side most pedagogues and psychologists regard the didactics of mathematics as part of the disciplines of education. Affinity for mathematics arouses suspicion and quickly qualifies the mathematics educator as a narrow-minded specialist of mathematics. What are the expectations of practicing teachers for mathematics educators? In their eyes mathematics educators should have about 10 years teaching practice and should continuously be involved in school life, at best by part-time teaching. The theoretical investigations carried out by mathematics educators are conceived of as unnecessary, if not obnoxious, digressions.

Tensions between didacticians of mathematics and academians in the reference fields arising from these role expectations are sometimes very hard to endure, particularly when the mathematics educators form no department of their own but are integrated into the departments of mathematics or education. Nevertheless, I do not recommend a surrender to the temptation of reducing the tensions by one-sided adaptation. This would inevitably widen the gap to the other fields of reference and would invalidate the tasks of mathematics education. Frankly speaking I think it a sign of weakness. It should be beneath the didactician's dignity to adapt to the environment like a chameleon.

Instead I would like to argue strongly in favour of an independent didactics of mathematics, and I consider the problems of relating the didactics of mathematics to mathematics, to the educational disciplines, and to teaching practice as completely natural problems which should be made conscious, in order to stimulate the mutual crossings of borders. I am deeply convinced that in the long run this will be profitable not only for mathematics education but also for the fields of reference.

Progress in solving the problems of integration mentioned above is of particular importance for teacher training, as most teacher training programmes consist of iso- 
lated mathematical, educational, didactical and practical components. Also, research in mathematics education very often lacks the interlocking of different aspects.

The following approach to integrating the various aspects of mathematics education originated in the reform of our teacher training programs at Dortmund University initiated by the 1976 teacher training law of North Rhine-Westphalia. Actually I will restrict myself to teacher training for the primary level, because in this area we have made the greatest progress; however, I am convinced that our approach can easily be transferred to the other levels.

Of course we are not the first ones trying to reform teacher training by integrating different components, neither are we the first ones to use teaching units for this purpose. Therefore I do not believe the approach of this paper to be totally new; however, I think it worthwhile to elaborate the full momentum of the "philosophy of teaching units" in a systematic and comprehensive way. The main part of this paper will be devoted to that task.

\section{Some Views on Mathematics Teaching}

A more detailed analysis of the problems of integration in Sect. 2 leads very quickly to uncovering an inconsiderate use of language in discussions on teacher education which is responsible for obscurities and misunderstandings, as well as for seeming consensus: the terms "mathematics", "psychology", "pedagogy", "mathematics education", "teaching practice", etc., are tacitly assumed to have a definite meaning, although quite to the contrary, all these fields more or less obviously admit of varieties of very differently marked points of view.

With respect to this plurality of views it is hopeless from the very beginning to establish relationships in general and to combine any conception of didactics of mathematics with any conception of mathematics, with any kind of teaching practice, etc. I see no other way out of this situation than to start from some basic educational view on mathematics teaching and to select those attitudes towards mathematics, psychology, pedagogy and teaching practice which are compatible with this fundamental view. I am well aware that this approach explicitly involves subjectivism. However, subjectivism is already implicitly present and, moreover, there is always room for intersubjective agreement anyway.

The fundamental idea of mathematics teaching which is at the heart of the proposed approach—my ideology so to speak — is the following one:

Mathematics teaching is doing mathematics with students in order to cultivate their understanding of reality.

Of course this "axiom" is nothing but a short formulation of a "genetic" view on mathematics teaching which has been developed elsewhere in detail (cf. Wittmann 1980b).

What are the consequences of this position for the fields surrounding the didactics of mathematics? 
As far as mathematics is concerned, the genetic view of mathematics teaching emphasizes the dynamics of mathematics, its applications in small and big problems, the processes of solving problems, the relationships within mathematics, as well as to the outside world. Clearly this view is in sympathy with the lively picture of mathematics as described in Lakatos (1976), not with the anaemic skeleton usually presented to freshmen students.

Concerning psychology, those theories are of particular interest which are based on the learner's active search and which consider the learner's prerequisite knowledge as a crucial factor in the learning process. A typical example of this is J. Piaget's genetic epistemology and psychology.

Finally, within pedagogy both theories and methods of social learning have to be emphasized.

I would like at least to indicate the consequences to be inferred from these evaluations for the training of mathematics teachers. In order to be able to do mathematics with pupils the student-teacher needs:

(1) sufficient mathematical training in order to do mathematics at an appropriate level above the school curriculum;

(2) psychological training which introduces him or her to observing, analysing and understanding the successful and non-successful mathematical thinking processes of students;

(3) pedagogical training which incorporates understanding for social learning.

It is obvious that to achieve these goals we need teacher training programs quite different from most present ones. However, I cannot go into details here.

\section{Teaching Units as the Integrating Core of Mathematics Education}

The central thesis of this paper is this:

In order to establish relationships between the different aspects of mathematics education and between the corresponding components of teacher training as well, it is useful to start from entities which already represent integration in a natural way, namely teaching units. Appropriate teaching units provide opportunities for doing mathematics, for studying one's own learning processes and those of students, for evaluating different forms of social organization, and for planning, performing and analysing practical teaching. Therefore teaching units are a unique means for penetrating all components of teacher training and relating them to one another.

Finally, teaching units offer an excellent way for applied research into mathematics teaching.

I would like to illustrate this "philosophy of teaching units" by means of some special units. 


\subsection{Some Teaching Units}

In my teacher training courses I regularly present a teaching unit (TU) in a format which involves brief information on: objectives $(\mathrm{O})$, materials $(\mathrm{M})$, mathematical problems arising from the context of the unit (P) and the-mostly mathematical, sometimes psychological—background of the unit (B). During the course these components are explained as much as I judge necessary.

The first three of the following examples are taken from the didactics of the primary level, the fourth from the secondary level.

\subsection{1}

TU Arithmogons (McIntosh and Quadling 1975; Walther 1978)

$\mathrm{O}$ : Adding, subtracting, operative investigation of these operations, searching-discovering.

M: Trigonal and quadrilateral arithmogons (partly on worksheets).

P: Given numbers in some vertices and edges. Find the other numbers!

B: Linear independence of the numbers in vertices and edges, systematic solution by means of systems of linear equations, operative principle. ${ }^{1}$

As a reminder, arithmogons are triangles, quadrilaterals, in general $n$-gons, whose sides and vertices can be labelled by numbers according to the following rule: Each number in a side is the sum of the numbers in the adjacent vertices (cf. Fig. 2)

I'll come back to the mathematical background later.
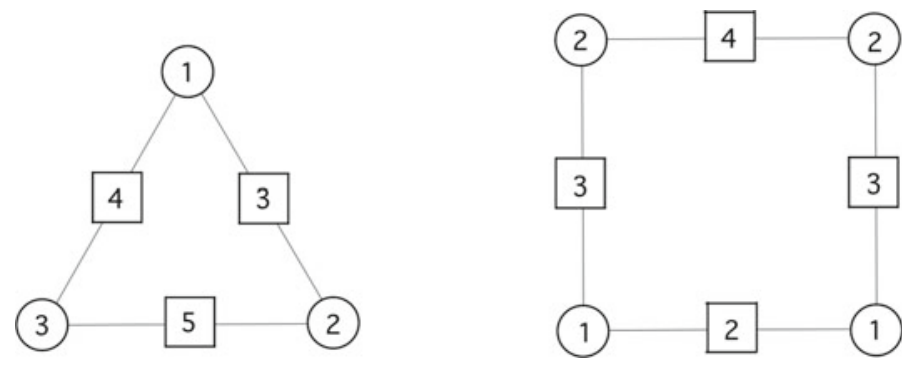

Fig. 2 Arithmogons: examples

\footnotetext{
${ }^{1}$ The operative principle is explained in Wittmann (1980b), Chap. 8.
} 


\subsection{2}

TU "Chinese Remainder Theorem"

$\mathrm{O}$ : Dividing with remainder, discovering, explaining.

M: Number line (integers).

P: $\quad$ Find a number which when divided by 3 leaves the remainder 1 and when divided by 4 leaves the remainder 2 .

Find another number of this kind.

Find another one, ... etc.

Can you find a pattern?

B: Chinese Remainder Theorem.

\subsection{3}

TU Mini-Group-Ticket (Wittmann 1980a)

$\mathrm{O}$ : Combinatorial counting, adding, subtracting, halving of amounts of money, mathematizing real situations, interpreting texts, reading tables.

M: Folder of the German Railway.

$\mathrm{P}$ : What is a mini-group ticket?

What is a mini-group?

How many mini-groups exist?

How much can you save by using a mini-group ticket?

B: Combinatorial counting, computational algorithms for addition and subtraction, functions.

\subsection{4}

TU Galton Board (Schupp 1976)

$\mathrm{O}$ : Mathematizing a stochastic situation.

M: Galton boards of various sizes, balls.

P: Where will the first ball fall?

Where will the second one fall?, etc.

Why?

What path can a ball take?

How many paths exist?

Which paths lead to the same goal?

Compare the probabilities of the paths, etc.

B: Bernoulli-chain, binomial distribution.

The examples are intended to show that a teaching unit in the sense of the present paper is not yet an elaborated plan for a series of lessons, although each one contains essential points of such a plan. Rather a teaching unit is an idea or a suggestion for a teaching approach which intentionally leaves various options of realisation open. 


\subsection{Teaching Units in Teacher Training}

First I would like to show how teaching units can be used within different components of teacher training.

In didactical training proper, teaching units serve as illustrations of didactical conceptions of teaching certain mathematical ideas or concepts. In this sense Gerhard Müller and myself wrote a book for primary student teachers (Müller and Wittmann 1978), half of which consists of 24 carefully selected teaching units. These units represent the essential content, objectives, and materials of mathematics teaching at the primary level. On the other hand teaching units are useful references in courses on general didactical principles. Unit 4.1.1, for example, involves an application of the operative principle; unit 4.1.3 is a model for the genetic principle (see Wittmann 1980b, Chap. 10). My own experiences in teacher training have convinced me that lectures on basic issues of mathematics teaching are hard to bear, both for the professor and for the students, without reference to concrete teaching units.

In other words, the value of teaching units for didactical training is based on the fact that they organise didactical knowledge in an effective way for mathematics teaching.

As for mathematical training, arithmogons, for example, fit perfectly into a course on algebra for primary and secondary students. Students may first investigate arithmogons on their own and develop their own strategies for solving them.

There are different types of tasks.

(a) The numbers in the circles are given.

(b) Some numbers in the circles and some numbers in the squares are given.

(c) Only the numbers in the squares are given.

While in cases (a) and (b) the missing numbers can easily be determined by addition and subtraction, in case (c) problem solving strategies are needed. It turns out that trigonal arithmogons have always exactly one solution, while quadrilateral arithmogons have either no or more than one solution.

These experiences pave the way for a systematic algebraic treatment of arithmogons (McIntosh and Quadling 1975): The numbers $x_{1}, x_{2}, \ldots, x_{n}$ in the vertices and the numbers $y_{1}, y_{2}, \ldots, y_{n}$ in the edges of an $n$-gon (cf. Fig. 3) are related to one another by the linear equations

$$
x_{1}+x_{2}=y_{1}, \quad x_{2}+x_{3}=y_{2}, \ldots, x_{n}+x_{1}=y_{n} .
$$




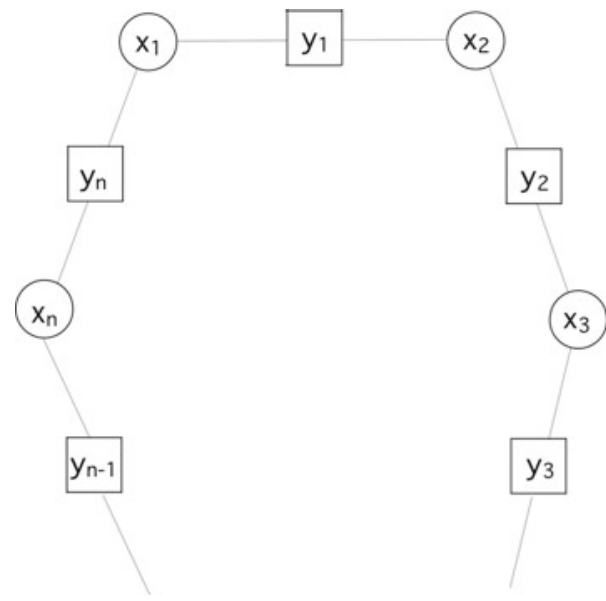

Fig. 3 Arithmogons: general setting

In other words, the mapping $\varphi$ assigning the $n$-tuple $\left(x_{1}, \ldots, x_{n}\right)$ to the $n$-tuple $\left(y_{1}, \ldots, y_{n}\right)$ is a linear mapping of $\mathbb{Q}^{n}$ (or $\mathbb{R}^{n}$ ) into itself. Transforming the corresponding matrix shows that $\varphi$ is of rank $n$, if $n$ is odd and of rank $n-1$, if $n$ is even.

In the same manner the other units give rise to genuine mathematical work, as is indicated by the cues describing the mathematical background and need not be elaborated in detail here.

On the whole, I hope to have made clear that teaching units may serve as starting points for substantial mathematical activities on which important mathematical theories can be built. These theories are then obviously related to mathematics teaching. So prospective teachers will not think them irrelevant or useless, as is so often the case in today's teacher training. In my opinion a change of mathematical training towards the direction described here is one of the most urgent tasks in reforming teacher education.

As far as the practical training is concerned, it almost goes without saying that students should elaborate and test teaching units which they have met during their didactical training. In my opinion the crucial point for planning a lesson is to make the content or skills to be taught accessible by means of appropriate problems (cf. Wittmann 1980b, Chap.5). This is the reason why "problems" is one of the four items to be considered in a teaching unit.

Videotaped units are very useful for illustrating didactical ideas and for stimulating students. In Dortmund we are going to establish a collection of videotapes of our favourite teaching units.

Because it is very difficult to study thinking processes of individual children in the classroom, student teachers should be offered psychological-didactical studies which introduce them to clinical interviews (cf. Herscovics and Bergeron 1980). My own approach to this field (Wittmann 1982) does not primarily use themes from the 
psychological literature, but rather, as might be expected, psychological problems arising from teaching units. For example, unit 4.1.3 poses the questions 'Which strategies do primary children use to find mini-groups?' and 'How many do they discover?' (cf. Heßler et al. 1980).

Last but not least, I should explain how to rethink the pedagogical training from the point of view of teaching units. In principle, teaching units are open to pedagogical considerations, too. I would like to refer here to teaching units which were especially devoted to organizing social activities (Müller and Wittmann 1978, Chap. 1.5.1, pp. 116 ff., Chap. 1.5.4, pp. 128 ff.; Wittmann 1977).

As mathematics educators are usually not as responsible for the pedagogical training as they are for the other components of teacher training, they cannot exert too much influence in this direction. It is important that pedagogues pick up teaching units and deepen them pedagogically.

\subsection{Teaching Units in Didactical Research}

Empirical research in mathematics education at the international level seems more and more in favour of clinical studies (Easley 1977). As long as such studies are done outside the natural context of learning and teaching and as long as they are directed towards basic research, however, they do not provide us with the knowledge necessary for guiding the learning of specific contents and procedures. For many years $H$. Freudenthal has developed a conception of mathematics education which is centered around the study of open and guided mathematical learning processes (cf. Freudenthal 1978). I would like to go a little step further and suggest that researchers investigate the mathematical thinking of pupils by using the framework provided by a series of didactically rich and widely accepted teaching units. The studies of Schupp (1976) with respect to unit 4.1 .4 as well as those of Bell (1976), Galbraith (1981), may serve as models. Research of this kind would be immediately applicable to mathematics teaching by its very design. It would always include certain content and thus keep us away from unjustified generalisations over other contents.

The methodical degrees of freedom, offered when turning a variable teaching unit into a definite one, should be used by researchers in systematic variations of the conditions.

I would like to embed the "philosophy of teaching units" described in this paper into the methodology of the "Sciences of the artificial" created by the American Nobel Prize Winner Herb Simon (Simon 1970). Teaching units are just artificial objects constructed by mathematics educators, and it is my proposal to investigate the behavior and the adaptability of these objects to different educational ecologies. 


\section{Conclusion}

The English group theorist Graham Higman once remarked "that progress in group theory depends primarily on an intimate knowledge of a large number of special groups". I believe that mathematics education could equally take substantial profit from the intimate knowledge of a large number of special teaching units.

This is not to question the importance of more general aspects of mathematics teaching beyond or independent of particular teaching units. Quite to the contrary: Just as group theory does not consist of a list of special groups, but is a theory surrounding and surmounting special groups, didactics of mathematics can only be viewed as a theory of and beyond real teaching.

Acknowledgements The author is indebted to Dr J. P. Becker, Carbondale, Illinois, for critical comments.

\section{References}

Bell, A.W.: A study of pupils' proof-explanations in mathematical situations. Educ. Stud. Math. 7, 23-40 (1976)

Bigalke, H.-G., et al.: Didaktik der Mathematik. Zentralblatt für Didaktik der Mathematik 109-132 (1974)

Easley, J.: On clinical studies in mathematics education. The Information Reference Center for Science, Mathematics and Environmental Education, Columbus, Ohio (1977)

Freudenthal, H.: Weeding and Sowing. Reidel, Dordrecht (1978)

Galbraith, P.L.: Aspects of proving: a clinical investigation of process. Educ. Stud. Math. 12, 1-18 (1981)

Herscovics, N., Bergeron, J.C.: The training of teachers in the use of clinical methods. Paper submitted to ICME IV Berkeley, Concordia University Montreal (1980)

Heßler, C., Kasper, S., Stüber, U.: Beobachtungen von Denkprozessen beim kombinatorischen Zählen am Beispiel "Mini-Gruppen-Karte", Seminarbericht SS 1980, pp. 1-20. Universität Dortmund, Institut für Didaktik der Mathematik (1980)

Lakatos, I.: Proofs and Refutations. Cambridge University Press, Cambridge (1976)

McIntosh, A., Quadling, D.: Arithmogons. Math. Teach. 70, 18-23 (1975)

Müller, G., Wittmann, E.: Der Mathematikunterricht in der Primarstufe. Vieweg, Braunschweig (1978)

Schupp, H.: Einführung in stochastisches Denken anhand des Galtonbrettes. Beiträge zum Mathematikunterricht 202-205 (1976)

Simon, H.A.: The Sciences of the Artificial. M.I.T Press, Cambridge (1970)

Walther, G.: Arithmogons - eine Anregung für den Rechenunterricht in der Primarstufe. Sachunterricht und Mathematik in der Primarstufe 6, 325-328 (1978)

Wittmann, E.: Die Geometrie der Schulmilchtüten und die lokalen Experten. Beiträge zum Mathematikunterricht 307-310 (1977)

Wittmann, E.: Die Mini-Gruppen-Karte der Deutschen Bundesbahn. In: Vollrath, H.-J. (ed.) Sachrechnen, Stuttgart, pp. 124-135 (1980a)

Wittmann, E.: Grundfragen des Mathematikunterrichts. Vieweg, Braunschweig (1980b)

Wittmann, E.: Mathematisches Denken bei Vor- und Grundschulkindern. Eine Einführung in psychologisch-didaktische Experimente. Vieweg, Braunschweig (1982) 
Open Access This chapter is licensed under the terms of the Creative Commons Attribution 4.0 International License (http://creativecommons.org/licenses/by/4.0/), which permits use, sharing, adaptation, distribution and reproduction in any medium or format, as long as you give appropriate credit to the original author(s) and the source, provide a link to the Creative Commons license and indicate if changes were made.

The images or other third party material in this chapter are included in the chapter's Creative Commons license, unless indicated otherwise in a credit line to the material. If material is not included in the chapter's Creative Commons license and your intended use is not permitted by statutory regulation or exceeds the permitted use, you will need to obtain permission directly from the copyright holder. 